\title{
Quantification of transformation and transport across biogeochemical boundaries by multi-element CSIA
}

BARBARA SHERWOOD LOLLAR ${ }^{1}$, ELIZABETH PHILLIPS ${ }^{1}$, ANN S. OJEDA ${ }^{1}$, WEIBIN CHEN $^{1}$, TETYANA GILEVSKA ${ }^{1}$

${ }^{1}$ Dept. of Earth Sciences, 22 Russell St., University of Toronto, Toronto ON Canada M5S 3B1

(Correspondence: barbara.sherwoodlollar@utoronto.ca)

The expansion of multi-element $(\mathrm{C}, \mathrm{H}, \mathrm{Cl}$ and other) compound specific isotope analysis provides novel insights into processes controlling the transport and fate of volatile organic contaminants in the environment, but also new technological and methodological challenges. This talk will address recent developments in high resolution monitoring of stable isotope signatures for organic hydrocarbon pollutants in groundwater. High resolution sampling on a cmscale resolution of contaminated groundwater discharging across the sediment-water interface integrates the concept of representative elemental volume that has been widely investigated in the context of many primary hydrogeological parameters (e.g. hydraulic conductivity, porosity) but not typically addressed in the context of CSIA. Results demonstrate not only the ability to identify processes of biodegradation, but to pinpoint critical intervals within which the relative rates of biodegradation, diffusion and advective transport undergo significant change in the balance of their contribution to contaminant fate. Such approaches can identify protective zones within the subsurface where biodegradation is reducing contaminant loads, identify intervals requiring further investigation through application of additional MBTs (microbiological tools), and development of novel tools such as in situ quantification of biodegradation rates. 